\section{LES BARQUES DE PAS I EL RETAULE DE SANT BERNADÍ DE SIENA (1455-1456) DE L'ESGLÉSIA DE SANT FRANCESC D'ESTAMPATX (CÀLLER, SARDENYA $)^{1}$}

La iconografia és un recurs de primer ordre per tal de documentar amb imatges allò que trobem en altres fonts d'informació, com ara l'escrita — ja sigui arxivística o literària — o fins i tot l'arqueològica, l'estudi de la cultura material, tot i que en aquest darrer cas tot allò que és d'origen orgànic sol desaparèixer i, per tant, sols es conserva el material inorgànic —i sovint fragmentàriament- Totes tres fonts d'informació ajuden I'historiador a conèixer millor el passat a través dels objectes, les imatges i les paraules.

En l'àmbit de la construcció naval, la iconografia d'època baixmedieval ens ha estat de gran ajut pel detallisme i realisme de les embarcacions representades als retaules gòtics i altres obres del mateix període. Cal destacar, però, que no tots els tipus navals hi surten representats; és a dir, hi ha una sobrerepresentació dels grans vaixells de comerç — com ara les coques i les naus-, que vesteixen les escenes de viatges i miracles de les vides dels sants relacionats amb el mar. Aquesta sobrerepresentació és causada en bona part per les aportacions monetàries i el finançament de retaules per part de mercaders enriquits gràcies al comerç marítim i que, per tant, tenien un interès especial per veure la màquina o el vehicle que havia permès transportar les seves mercaderies de Barcelona a Alexandria i Flandes. ${ }^{2}$ D'altra banda, tenim un munt $d^{\prime}$ embarcacions de pesca per la presència obligatòria $d^{\prime}$ 'aquestes a les escenes on es representen els apòstols pescadors sant Pere i sant Andreu, a més del martiri de sant Vicenç. La resta d'embarcacions de I'ampli repertori naval no solen aparèixer mai en la iconografia naval, ni les embarcacions militars com la galera, ${ }^{3}$ ni els vaixells mercants de port mitjà, com els llenys, ni les embarcacions menors dedicades al comerç de cabotatge 0 als treballs portuaris.

A més, volem subratllar que en la iconografia se sol representar l'obra morta d'una embarcació, de la línia de flotació fins a la coberta, a més de I'aparell, ja que I'obra viva queda sota I'aigua. Aquesta és una gran diferència respecte a les restes arqueològiques conservades d'embarcacions medievals, que solen correspondre gairebé sempre al fons del buc, és a dir,
MATÈRIA, núm. 16-17, 2020, ISSN 1579-2641, p. 29-43

Recepció: 11-1-2019

Acceptació: 7-11-2019

${ }^{1}$ El treball forma part del projecte de recerca «Moviments $\mathrm{i}$ mobilitats a la Mediterrània medieval. Persones, termes i conceptes» (PGC2018-094602B-100, Ministeri de Ciència, Innovació i Universitats), dirigit per la Dra. Roser Salicrú i Lluch.

2 Els vaixells mercants (naus i coques, bàsicament) han estat objecte d'estudi per la seva relació amb els passatges bíblics i I'hagiografia a: Marta NUET BLANCH, «El salvamento de náufragos, metáfora de la penitencia en el gótico catalán», Locus Amoenus, núm. 5, 20002001, p. 53-65; Francesca EsPAÑOL BERTRAN, "Le voyage $\mathrm{d}^{\prime}$ outremer et sa dimension spirituelle. Les sanctuaires maritimes de la côte catalane», M. Bacci, M. Rohde (eds.), The Holy Portolano. The Sacred Geography of Navigation in the Middle Ages, Berlín, De Gruyter, 2014, p. 321-359. D'altres els han estudiat per la seva tecnologia (propulsió, direcció): 
Àngels Casanovas, «El timón según la iconografía medieval catalana», Archaeonautica, núm. 11, 1993, p. 165-185; Guillem Rosselló Bordoy, «Navegación y avances técnicos: un análisis iconográfico», El poder real en la Corona de Aragón (siglos XIV-XVI), vol. V, Saragossa, Gobierno de Aragón, Departamento de Educación, Cultura y Deporte, 1996, p. 449-474. També s'han publicat casos concrets: Lawrence $V$. MotT, «Medieval ship graffito in the Palau Reial Major at Barcelona», The Mariner's Mirror, vol. 76, núm. 1, 1990, p. 13-21; Antònia Victòria CARMona i Bustos, "Imatge catalana de 1360 d'una nau amb aparell rodó de tres pals», Estudis Històrics i Documents dels Arxius de Protocols, núm. XIV, 1996, p. 159-166; Joaquín YARZA LUACES, «¿Dibujos, esbozos, modelos?», J. Molina Figueras (ed.), Bernat Martorell i la tardor del gòtic català. El contextartístic del retaule de Púbol, Girona, Museu d'Art de Girona, 2003, p. 149-150; Marcel PuJoL I HAMELINK, «IConografia naval a I'església de Sant Miquel de Montblanc (Conca de Barberà)», Unicum, núm. 4, 2005, p. 132-136. I, finalment, cal destacar com a peça tridimensional excepcional el model d'una coca o nau catalana conservat avui dia al Maritiem Museum de Rotterdam: Heinrich Winter, Die Katalanische Nao von 1450, Magdeburg, Loef, 1956. Versió catalana: Heinrich WINTER, La nau catalana de 1450 (amb es- a I'obra viva. En certa manera, podríem dir que les dues fonts es complementen, igual com la documentació escrita posa nom a allò que veiem: la imatge i I'objecte.

És cert que en ocasions i gràcies a les innovacions arribades de l'art flamenc, el gòtic internacional va incorporar la representació del paisatge al fons de les escenes, en detriment de la superfície plana i daurada del gòtic anterior. Es tracta d'una novetat que enriqueix les escenes i que ens pot aportar informació sense tenir cap relació directa amb la vida i els miracles del sant a qui es dedica el retaule. Així, la figura del santoral representada no està relacionada amb la presència o I'absència d'embarcacions al fons de l'escena. Una veritable meravella que il.lustra aquest fet i la realitat d'un port mediterrani del segle XV és el retaule de sant Jordi de Pere Niçard, en el qual al paisatge del fons ens apareix el port de Mallorca, amb una riquesa naval, tipològica, qualitativa i quantitativa excepcional. ${ }^{4}$

Però si ens allunyem del mar i entrem en un altre àmbit aquàtic com són els rius i els llacs, ens tornem a trobar davant d'un buit figuratiu, des d'un punt de vista naval. És veritat que sant Pere i sant Andreu pescaven al mar de Tiberíades o Galilea —un mar interior-, però el que els artistes representen realment és una barca de pesca de la costa catalana. ${ }^{5} \mathrm{~A}$ banda d'aquesta barca de pesca —-marítima o bé lacustre-, no hi apareixen altres embarcacions d'aigües interiors. En algun retaule aragonès hi apareix al fons un paisatge amb rius i embarcacions representades d'una manera molt esquemàtica, que devien correspondre a les que van conèixer els artistes a l'Ebre i els seus afluents.

En molts cursos fluvials les embarcacions també hi eren presents com a transports, amb unes especificitats pròpies del medi per on navegaven. La navegació estava molt condicionada, d'una banda, pel cabal, la força i la fondària del riu i la presència de barreres (rescloses, peixeres, salts d'aigua), i, de l'altra, per l'adaptació de les embarcacions a la navegació fluvial (absència de quilla, arbre baix i situat a proa per a la sirga, tendència a allargar les embarcacions i tenir poc calat). La navegació es trobava present als grans cursos fluvials, com ara l'Ebre, on els llaguts de riu i altres tipus d'embarcacions pujaven i baixaven resseguint la seva longitud, des del delta cap a Tortosa i més amunt, pujant gràcies a l'existència del camí de sirga i baixant gràcies al corrent que els empenyia cap a la desembocadura. L'excepció en aquesta navegació fluvial eren els rais, que només feien el viatge en el sentit de la capçalera cap al delta; de fet, la mateixa embarcació era alhora transport i producte de comerç, per la seva fusta. ${ }^{6}$

En canvi, en la major part dels rius hi havia un altre tipus de navegació, en aquest cas no longitudinal, sinó transversal, amb les embarcacions 
que permetien una navegació perpendicular al curs del riu per anar d'una riba a l'altra quan no existia un pont o un gual: les anomenades barques de pas, de passatge 0 de llibant.

\section{Les barques de pas}

Un riu pot ser una barrera i alhora un lloc de pas. Les vies de comunicació terrestres, els camins, quan es troben davant d'una massa d'aigua, la salven voltant-la —en el cas d'un estany - o bé buscant aquell indret menys profund pel qual es pugui passar a peu, el gual d'un riu. Si no es troba o no és possible, cal un altre sistema per creuar el riu. Hi ha diferents maneres:

1. Gual o passera: tram de riu per on es pot passar a peu d'un costat a I'altre gràcies a la poca fondària del riu i a la facilitat de pas — ni fang ni pedres.

2. Palanca: construcció de fusta limitada a un conjunt de taules alineades per on només passen persones i algun animal.

3. Pont de fusta: estructura més complexa i sòlida per on poden passar persones, animals i carros.

4. Pont de pedra: estructura complexa i sòlida d'obra, morter de calç i pedra, per on poden passar persones, animals i carros.

5. Pont de barques: barques unides de riba a riba per una plataforma de pas que permet el pas de persones, animals i carros.

6. Pas de barca: un cap de riba a riba serveix de guia a la barca de passatge.

Totes aquestes solucions no són res més que la continuació de la via terrestre, en què les persones, els animals i els carros segueixen desplaçant-se, ja sigui tocant el fons del riu o per sobre de la superfície d'un pont, i sempre es tracta d'una superfície estàtica. L'excepció seria el pas de barca - i en certa manera també el pont de barques-, en què cal embarcar-se sobre un objecte que sura i es desplaça per la superfície de l'aigua.

A l'Edat Mitjana el camí ral que passava pels dos rius més cabalosos de Catalunya, el Llobregat i I'Ebre, els salvava a través del pont del Diable (o de Sant Bartomeu), a Martorell, d'origen romà, i del pont de Barques, a Tortosa. ${ }^{7}$ A la resta de passos del riu Ebre i del Llobregat, i en la pràctica totalitat de la resta de rius, es feien servir guals i barques de pas.

Si observem les imatges de les diferents barques de pas catalanes d'època moderna i contemporània, se'n poden arribar a distingir dos tipus, tudi annex de Santiago Hernández (zal), Barcelona, Diputació de Barcelona, 1986; Marcel PUJOL I HAMELINK, «El model de coca o nau catalana del segle $x v$ : un segle $d^{\prime}$ incerteses al voltant de la mal anomenada "Coca de Mataró"», Drassana. Revista del Museu Marítim, núm. 26, 2018, p. 55-82.

3 Lawrence V. MotT, «Ships of the 13th-Century Catalan Navy», The International Journal of Nautical Archaeology, vol. 19, núm. 2, 1990, p. 101112.

4 Marcel Pujol i Hamelink, «El retaule de Sant Jordi (1468-1471) de Pere Niçard i la seva aportació al coneixement de la iconografia naval», Unicum, núm. 16, 2017, p. 43-58.

5 Marcel Pujol i Hamelink, «Tecnologia i pesca a la Baixa Edat Mitjana: les embarcacions de pesca i l'art de la batuda a la costa catalana», Barcelona. Quadernsd'Història, núm. 21, 2014, p. 156-168.

${ }^{6}$ Es pot veure una imatge de rai al riu Segre al seu pas per Lleida en la vista realitzada I'any 1563 per Anton van den Wijngaerde.

7 Disposem d'una magnífica imatge del pont de Barques sobre el riu Ebre a Tortosa en la vista de la ciutat realitzada per Wijngaerde I'any 1563. Maria UTGÉs, «La construcció i manteniment del pont de barques a I'època baixmedieval», Albert CURTo (coord.), Lo Pont de Barques. L'antic pas de l'Ebrea Tortosa, Barcelona, Llibres de I'Índex, 1993, p. 45-73; Mont- 
serrat FARRENY, Alfred MAURI, Miquel VIVES, «La seqüència històrica del Pont del Diable i el seu context territorial», M. Gómez, G. Gutiérrez, M. LuenGo (eds.), Miscel/lània d'homenatge a Jaume Codina, el Prat de Llobregat, Columna, 1994, p. 219-250.

8 Aquest sistema també s'observa en altres grans rius navegables europeus, com ara el riu Roine.

9 No sembla que abans de la Guerra del Francès existissin barcasses formades per dos Ilaguts de riu a I'Ebre; anteriorment totes eren construïdes amb un sol llagut de riu. segons el sistema de desplaçament que utilitzen. El primer, que anomenem barca de gúmena i ramalet, s'utilitzava en el gran riu navegable català, I'Ebre, i el segon, que en diem barca de llibant i castell, era emprat en la resta de rius catalans que disposaren de barques de pas.

En principi la mecànica és la mateixa: un cap que uneix les dues ribes, al qual s'enganxa la barca de pas, permet que la barca passi d'un costat a I'altre del riu sense que el corrent se l'emporti riu avall.

La diferència entre I'un i I'altre té relació directa amb el fet que I'Ebre és un riu navegable. L'Ebre era utilitzat per transportar persones i mercaderies des del mar cap a l'interior i a la inversa; no només hi davallaven rais fins a la desembocadura, sinó que també el remuntaven diferents tipus d'embarcacions del delta a Tortosa, i d'aquí a Mequinensa i més amunt. En aquest cas, les embarcacions que naveguen riu amunt i riu avall no poden trobar l'impediment d'un cap que travessa el riu — tal com passa a la major part de rius europeus també navegables-; per tant, el cap travesser s'ha de col·locar molt enlairat, de tal manera que ni I'orla ni l'arbre de sirga del llagut que puja o baixa pel riu no arribin a enganxar-se amb el cap de la barca de pas. A l'Ebre, a causa de l'amplada del riu i del pes de la barca i el seu carregament, i sovint també per la força del corrent, el cap que travessa el riu ha de ser gruixut i resistent, per la qual cosa sempre es fa servir el cap més gruixut i fort que es pot trobar, la gúmena. Aquesta es Iligava a un arbre, a una estaca o a un torn a cada riba i travessava el riu a uns quants metres per sobre de la coberta de la barca de pas, motiu pel qual s'utilitzava un element intermediari entre la gúmena i la barca, un cap dit ramalet (o capet), que unia la gúmena a la barca. El ramalet disposava d'un joc de corrioles, conegut com a colladora (o calabrot), en el punt de contacte amb la gúmena que permetia que aquesta llisqués i corrés, cosa que facilitava el desplaçament transversal pel riu del conjunt de ramalet i barca (fig. 1). ${ }^{8}$

Però tampoc no totes les barques eren iguals. Podem trobar des d'una barca petita per passar persones als rius petits fins a barques més grans que anaven parcialment o totalment cobertades, o la utilització de dos 0 tres llaguts de riu amb una plataforma a sobre que els unia, com en el cas de I'Ebre. ${ }^{9}$

A la resta de rius catalans, com que no hi havia una navegació habitual que seguís el curs del riu amunt i avall, hi trobem el segon tipus de barca de pas, que anomenem de llibant i castell, en què les barques tenen un cap que travessa el riu i que no és tan llarg ni tan gruixut com la gúmena de I'Ebre; es tracta d'un Ilibant, que arriba a donar nom a la barca. El fet que no hi hagi navegació permet que el llibant estigui a un nivell més baix, just per sobre de la coberta de la barca, per la qual cosa en aquestes barques 


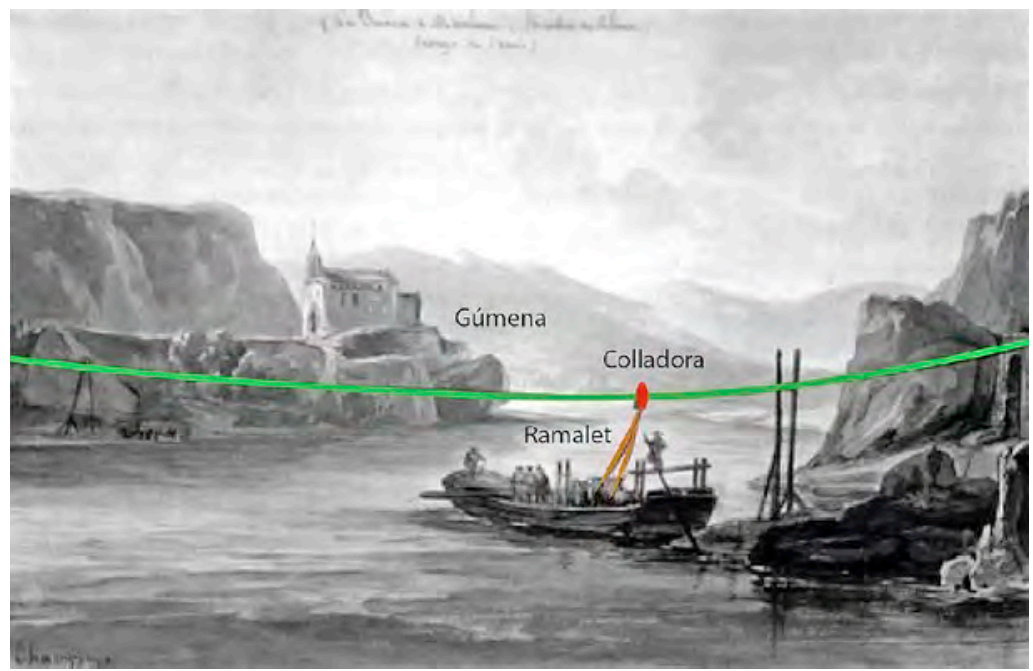

Fig. 1. Barca de gúmena, amb corriola i ramalet.

s'hi construeix una estructura de fusta, anomenada castell, per la qual s'introdueix el llibant i hi passa a través. En aquest cas, el ramalet i la colladora de les barques de pas de l'Ebre se substitueixen pel castell de les barques de llibant (fig. 2).

El retaule de sant Bernadí de I'església de Sant Francesc d'Estampatx és una obra que ens ofereix una escena que podem considerar pràcticament

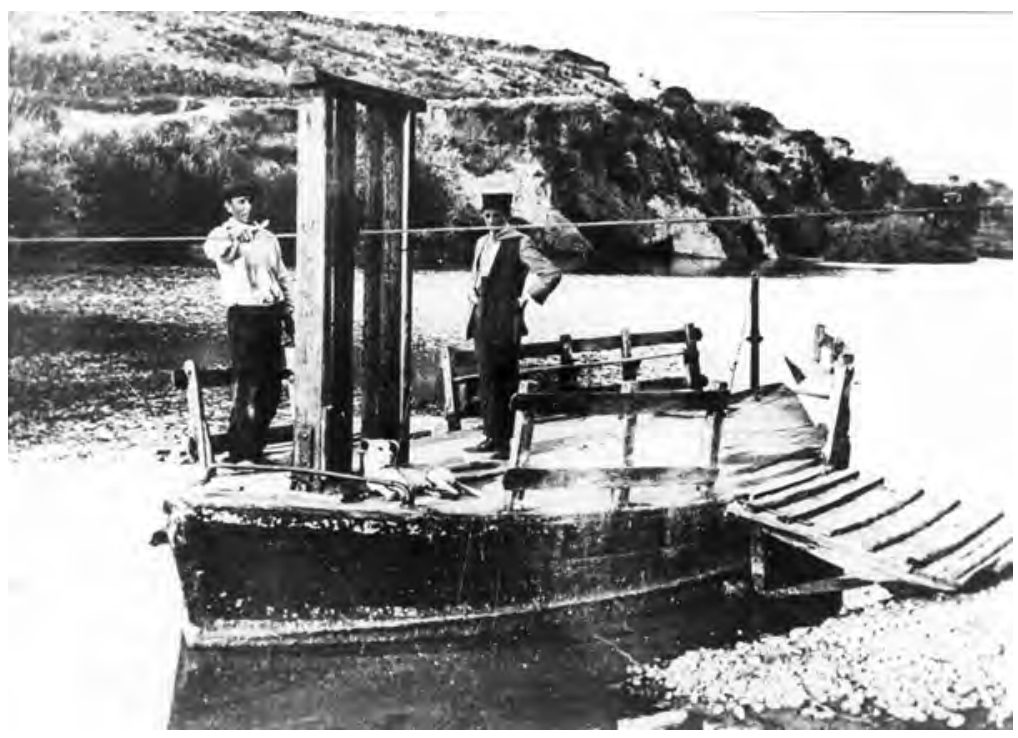

Fig. 2. Barca de llibant, amb castell a proa. 
10 Vegeu obra històrica de caràcter general sobre la conquesta i la presència catalana a Sardenya durant la Baixa Edat Mitjana a: Francesco Cesare Casula, Profilo storico della Sardegna catalano-aragonese, Cagliari, Edizioni della Torre, 1982; Mario DeL TREPPO, «L'espansione catalano-aragonese nel Mediterraneo», Nuove Questioni di Storia Medievale, Milà, Marzorati, 1964, p. 259-300; Valentina NonnoI (dir.), I/ regno di Sardegna in epoca aragonese. Un secolo di studi e ricerche. 1900-1999, Pisa, ETS, 2001; Vicente SALAVERT y RocA, Cerdeña y la expansión mediterránea de la Corona de Aragón (1297-1314), 2 vols., Madrid, Consejo Superior de Investigaciones Científicas Escuela de Estudios Medievales, 1956; Marco TANgheroni, "Il "Regnum Sardiniae et Corsicae" nell'espansione mediterranea della Corona d'Aragona. Aspetti economici», La Corona $d^{\prime}$ Aragona in Italia (secc. XIIIXVIII), Atti del XIV Congresso di Storia della Corona d'Aragona (Sassari-Alghero, 19-24 maggio 1990). I. Relazioni, Sàsser, Carlo Delfino, 1993, p. 49-88; Antonio Arribas PALAU, La conquista de Cerdeña por Jaime II de Aragón, BarceIona, Horta-Instituto Español de Estudios Mediterráneos, 1952; M. E. CADEDDU, «Giacomo II d'Aragona e la conquista del regno di Sardegna e Corsica», Medioevo. Saggi e Rassegne, núm. 20, 1995, p. 251316; Francesco Cesare CASULA, La Sardegna aragonese, 1. La única des del punt de vista de la representació de les barques de pas baixmedievals, d'un realisme i un detall que no coneixem en cap altra obra coetània i que ens mostra com eren les barques de pas que se seguiren utilitzant en bona part dels rius catalans fins al segle $x x$.

\section{Introducció. Descripció general de I'obra, els autors, lloc i data}

El retaule de sant Bernadí fou executat pels pintors catalans Rafael Tomàs i Joan Figuera, entre els anys 1455 i 1456, per a la capella central de la contrafaçana de l'església del convent de Sant Francesc d'Estampatx, a Càller. El motiu pel qual la presència catalana a Sardenya, també d'artistes, fou tan important durant el segle xv és conseqüència de la cessió de I'illa al comte rei Jaume II el Just per part del papa Bonifaci VIII I'any 1297, que creà el Regnum Sardiniae et Corsicae per dirimir el conflicte entre els Anjou i els catalans i el cedí en feu a canvi de reservar-se per a ell el regne de Sicília. Les paus d'Anagni i de Caltabellotta (19 d'agost de 1302) posaren fi a la guerra entre els Anjou i el casal de Barcelona, segons la qual el català renunciava a Sicília a canvi de I'oferiment del regne de Còrsega i Sardenya a la Corona d'Aragó. ${ }^{10}$

Sardenya, I'illa més gran de la Mediterrània occidental, havia estat en certa manera independent sota el govern dels jutges. L'illa estava dividida en quatre judicats - Torres, Càller, Gal-lura i Arborea-governats per jutges que tenien tot el poder civil i militar, però al llarg del segle XIII anaren caient sota la dependència de Pisa (Càller i Gal-lura) i Gènova (Torres); Arborea fou I'únic que es va mantenir independent fins a l'arribada dels catalans.

L'oferiment de Sardenya per part del papa (1297) i la pau de Caltabellotta (1302) no comportaren que la Corona d'Aragó prengués possessió de l'illa de manera efectiva, sinó que s'hagué d'ajornar per diverses raons, com ara l'estat de les finances reials en acabar la guerra amb els Anjou, la guerra a Sicília, la guerra amb Castella per Múrcia i Alacant (1296-1304) i la fallida conquesta d'Almeria (1309); tot un cúmul d'entrebancs que endarreriren la presa de l'illa de Sardenya fins a l'enviament de l'estol de conquesta l'any 1323.

La Corona n’havia de prendre possessió no només de paraula —o sobre el paper-, sinó que també havia de fer efectiu el control de l'illa i dels seus habitants, fet que només es podia aconseguir amb la presència d'un contingent humà (militar i administratiu) procedent de la Corona d'Aragó. L'operació era molt més complexa que la conquesta de Mallorca, per la 
distància, les dimensions de l'illa i la presència de pisans i genovesos reticents a la competència comercial catalana i a la cessió de l'illa al comte rei. L'únic suport que els catalans tenien a l'illa era el del jutge d'Arborea, I'únic dels quatre judicats que encara no havia caigut sota la dependència de pisans i genovesos.

L'estol de conquesta de Sardenya es reuní I'any 1323 al port Fangós, punt de concentració de la participació catalana i valenciana. Quan l'estol es desplaçà a Maó, es reuní amb l'estol mallorquí —el 1321 s'havia acordat que Sanç I de Mallorca hi participaria amb vint galeres, dos-cents cavalls i un gran nombre de peons-. En total es reuniren seixanta galeres, catorze naus i molts altres tipus d'embarcacions de port mitjà. D'altra banda, prèviament s'havia enviat cap a Sardenya una esquadra, com a avançada, per fer de cap de pont del gran estol que estava en ruta.

A partir del desembarcament a Palma de Sols I'any 1323, s'inicia la conquesta de I'illa, en què destaquen una sèrie de fets importants, com ara el setge i la capitulació de Càller (1326) o la batalla de Lucocisterna (1324), on els pisans són derrotats i, en capitular, cedeixen els drets que tenien sobre I'illa a Jaume el Just, excepte les ciutats de Castel di Castro, Vilanova i Estampatx. El 1325 es revolten els sards i genovesos de Sàsser i els sards i pisans de Càller. En la batalla naval de Càller (29 de desembre de 1325) s'enfrontaren I'estol de I'almirall Francesc de Carròs i de CruïIles i l'estol de vint-i-quatre galeres pisanes i genoveses comandat per I'almirall Dòria, que fou derrotat i totes les galeres, preses; Dòria se salvà saltant al mar i fugí nedant. El 1326 les dues ciutats, Sàsser i Càller, cauen en mans catalanes definitivament.

Càller fou repoblada amb catalans, que s'establiren fortament al nou nucli de Bonaire i també als altres nuclis urbans, tant a Estampatx com al Castell de Càller. La important presència catalana a Càller té la seva explicació en el paper de la ciutat i el seu port en la ruta de les Illes i de Llevant, rutes que unien la península Ibèrica amb la italiana, de Barcelona i València cap a Mallorca, d'aquí al sud de Sardenya —Càller-, Itàlia i Sicília i, finalment, de Messina cap a Llevant (Alexandria, Beirut, Rodes, Constantinoble). La presa de les Balears i Sardenya implicava controlar la ruta de les Illes i, amb Sicília, bona part de la ruta de Llevant.

Al cap d'uns decennis, I'aliança entre el comte rei i el jutge d'Arborea es trencà quan els sards, amb I'ajut de Gènova, es rebel-laren contra la Corona d'Aragó. En un principi el domini de l'illa va arribar a perillar, ja que els catalans van quedar reduïts pràcticament a Càller i I'Alguer. La reacció catalana, amb l'enviament de nous contingents des de Catalunya, va permetre derrotar els sards a la batalla de Sanluri (30 de juny de 1409) i ocupar Oristany, la capital del judicat d'Arborea (1410). La compra del
Corona d'Aragona; 2. La Nazione Sarda, Sàsser, Chiarella, 1990; Rafael Conde y Delgado de Molina, Antoni Maria Aragó Cabañas, Castell de Càller. Cagliari catalano-aragonese, Cagliari, Edizioni dell'Istituto sui Rapporti Italo-iberici del CNR, 1984. 
11 Tot i que hi ha part de la historiografia que proposa el 1478, amb la batalla de Macomer, com la desfeta dels Alagó, els últims pretendents del judicat d'Arborea.

12 Francesc Ruiz QuesadA, Joan Figuera. The Retable of the Virgin, Saint Peter Martyr, and Saint Mark, Madrid, Colnaghi, 2016, p. 12.

13 D. ScAno, "Avanzi e ricordi di un insigne monumento francescano», Unione Sarda, 16 octubre 1938. Hi ha la planta i les seccions de I'església i el claustre. Posteriorment s'han dut a terme altres estudis, de tipus arquitectònic, que es poden consultar a l'article d'E. PusceDDU, «Il retablo di San Bernardino...», Matèria, núm. 9, 2015, p. 39-60, vegeu p. 158 i nota 21.

14 Guido de Doni fou enterrat el 1410 en aquesta església, segons consta a la làpida —avui dia, el retaule i la làpida es conserven a la Pinacoteca Nazionale de Càller-. El 1399 Gerard Doni és propietari d'una nau baionesa d'un timó i dues cobertes feta construir a BarceIona, dedicada al comerç amb Alexandria i Anglaterra. S'estableix a Sardenya el 1404 amb I'arribada de Martí el Jove. El 1409 Gerard Doni comanda I'estol de vuit galeres que salparen de Càller per participar en la batalla d'Asinara contra els genovesos, de la qual els catalans surten victoriosos. El 1403 Leonardo de Doni actua de testimoni en un acte patrimonial de Joan Mates, autor del retaule de I'Anunciació (1406-1410) de la capella homònima, sota judicat d'Arborea per Alfons el Magnànim el 1420 implica el final de la guerra de conquesta, amb I'excepció de Castelsardo, que és pres el 1448. ${ }^{11}$

A partir d'aquesta data s'inicià un Ilarg període de pau i prosperitat en què la presència catalana marcà profundament la ciutat de Càller, encara amb més intensitat que durant el segle precedent (a banda de l'Alguer, que havia estat totalment repoblat amb catalans). Des d'un punt de vista artístic, entre els anys 1325 i 1450, arran de la presència catalana a l'illa, sobretot a Càller, que exercia de capital, i a altres indrets catalanitzats com ara I'Alguer, s'encarregaren obres religioses que foren realitzades per diferents tallers d'artistes de Catalunya, entre els quals destaquen, el 1364-1365, I'artista Llorenç Saragossa, amb un retaule dels sants Antoni i Gabriel per al duomo de Càller; el 1399 Pere Serra rep I'encàrrec de fer un retaule per al mercader Lleonard de Doni; el 1403 Joan Mates continua la relació amb Doni, establert a Càller, per fer un retaule per a I'església de Sant Francesc d'Estampatx, a Càller; el 1425 Jaume Vergós I és contractat per mercaders de I'Alguer, com ara Joan Maxau i Pere Partagàs, i apareix també Lleonard de Doni; el 1433 es contracten els pintors Pere Saclosa i Pere d'Euna; el 1452 Bernat Martorell rep quaranta Iliures per realitzar un retaule destinat a Sardenya, i el 1455 Llorenç Madur, pintor del taller dels Vergós, es trasllada a Sardenya. ${ }^{12}$

\section{L'església de Sant Francesc d'Estampatx}

L'església de Sant Francesc d'Estampatx es començà a construir poc després que els franciscans compressin el terreny l'any 1275. La construcció seguí un estil romànic pisà — de fet, el barri extramurs d'Estampatx fou creat pels pisans al segle XIII-, mentre que les ampliacions, com ara la nova coberta, les capelles i el claustre, construïdes durant els segles XIV i $X V$, seguiren I'estil gòtic català. ${ }^{13}$

El convent de Sant Francesc d'Estampatx, un edifici imponent, estava estretament Iligat als interessos econòmics de la burgesia mercantil sardocatalana. Sabem que, a la seva església, la capella de I'Anunciació estava sota la protecció de la família dels Doni (família d'origen pisà establerta a Barcelona $)^{14}$ i el retaule era obra de Joan Mates (1406-1410); a la capeIla de la Visitació hi feu un retaule el tortosí Joan Barceló, actiu a l'illa entre 1488 i 1516, i, finalment, tenim el retaule de sant Bernadí (1456) per a la capella central de la contrafaçana de l'església, del qual parlarem amb més detalls en l'estudi que presentem. 


\section{El retaule de sant Bernadí de Siena}

El 22 de febrer de 1455 els pintors Rafael Tomàs, de Barcelona, i Joan Figuera, de Cervera, acorden amb el mercader Francesc Oliver, entre d'altres, realitzar un retaule dedicat a sant Bernadí ${ }^{15}$ per al convent de Sant Francesc $d^{\prime}$ Estampatx. El contracte ${ }^{16}$ és signat pel frare i guardià del convent, Miquel Gros, pel mercader Francesc Oliver ${ }^{17}$ i pels dos artistes, que es comprometen a presentar un dibuix de la vida de sant Bernadí sobre una mostra de paper. En el contracte s'obliguen a enguixar i a pintar amb colors d'olis, ben historiat amb or fi, atzur i altres colors, tot per un valor de 360 lliures de Càller (I'equivalent a 240 florins d'or d'Aragó o 2.640 sous), que es cobraran per terminis: $1 / 3$ en començar, $1 / 3$ quan estigui mitja feina feta i $1 / 3$ en acabar, al cap d'un any d'haver començat I'obra. ${ }^{18}$ Pel que sembla, el mercader Francesc Carbonell, de Càller, fou qui va donar 200 florins d'or d'Aragó perquè Rafael Tomàs i Joan Figuera fessin el retaule de sant Bernadí, de setze compartiments i 3,98 m d'alt per 2,61 m d'ample. ${ }^{19}$

Dels dos autors sabem que Rafael Tomàs, originari de Barcelona, ja era a Sardenya el 1454, en companyia de I'argenter Leonardo Cani. Un cop signat el contracte, lloguen una casa a Càller a Pere de Llobera, mercader, a fora de la vila, prop de I'hospital de Sant Antoni, per dos florins I'any (un florí en començar el retaule i el segon en tenir-lo mig fet). Durant la realització del retaule Joan Figuera esmenta que és originari de Cervera (17 de juliol de 1455). ${ }^{20}$

Probablement el retaule s'acabà en el termini d'un any, tal com s'havia acordat en el contracte, atès que consta que el 24 d'abril de 1456 Rafael Tomàs era a Nàpols. Cap a finals d'any, el 16 de novembre, torna provisionalment a Càller per temes pendents, però I'any següent, el 1457, torna a ser a Nàpols, on el trobem associat a altres pintors, com ara Jacopo Barreta, Paolo Burriello i Francesco Pagano. Tot sembla indicar que el 1463 Rafael Tomàs deixa Nàpols i es trasllada a Perpinyà, on aquell any realitza una peça d'altar per a l'església de Sant Jaume i el 1470 treballa al cor de I'església de Sant Mateu amb Guillem Martí, el qual mantenia una forta relació amb Martorell. Rafael Tomàs mor en aquesta ciutat el $1471 .^{21}$

En canvi, Joan Figuera continuà vivint i treballant a Càller fins a la seva mort, probablement el 1477. Visqué en una casa amb dues botigues al carrer dels Mariners del Castell de Càller. Va ser autor d'altres retaules, com el dels sants Pere Màrtir i Marc Evangelista per a la capella del gremi de sabaters (col-lecció Piero Tozzi, Nova York), ${ }^{22}$ al claustre de Sant Domènec de Càller, i de la predel·la de sant Lucífer, de I'església de Sant Bardilio de Càller (Pinacoteca Nazionale, Càller), ${ }^{23}$ i, amb dubtes, potser també fou protecció dels Doni, a l'església de Sant Francesc d'Estampatx. Maria Grazia Scano NaItzA, «Presències catalanes a la pintura de Sardenya», A. PLADEVALL I FONT (dir.), L'art gòtic a Catalunya, Pintura, vol. III, Darreres manifestacions, Barcelona, Enciclopèdia Catalana, 2006, p. 246. Claude CARRÈRE, Barcelona 1380-1462. Un centre econòmic en època de crisi, vol. I, Barcelona, Curial (Documents de Cultura, 11), 1977, p. 221, 250-251; Arcadi García I SAnz, Maria Teresa Ferrer i Mallol, Assegurances i canvis marítims medievals a Barcelona, Barcelona, IEC (Treballs de la Secció de Filosofia i Ciències Socials, VII), 1983, vol. II, p. 431-432.

15 Bernadí de Siena (13801444) ingressà a l'orde dels framenors després que la ciutat de Siena hagués patit una plaga i una gran mortaldat I'any 1400. Bernadí donà tots els seus béns i posteriorment esdevingué un gran orador i autor de diversos miracles. Va ser canonitzat pocs anys després de la seva mort, el 1450.

16 Carlo ARU, "La pittura sarda nel Rinascimento. II. I documenti d'archivio", Archivio Storico Sardo, vol. XVI, CàIler, 1926, p. 194-195.

17 Francesc Oliver era un dels mercaders catalans més importants de la ciutat de Càller. El 1456 esdevingué cònsol primer de Càller; el mateix any va formar una companyia mercantil amb el seu germà, Bernat, resident a Barcelona, i un altre mercader, Francesc Carbonell, 
de Càller, per un valor de tres mil florins d'or d'Aragó, durant un període de quatre anys i amb la seu central a Barcelona. Alberto BOscoLo, «Una societat comercial a la Sardenya catalana», Estudis d'Història Medieval, núm. 3, 1970, p. 123-126.

18 M. G. ScANo, "Presències catalanes...», p. 247-249.

19 A. Boscolo, «Una societat...», p. 123-126.

20 E. Pusceddu, «Il retablo di San Bernardino...», p. 146, nota 2.

21 E. Pusceddu, «II retablo di San Bernardino...», p. 146, nota 2.

22 En aquest retaule apareix una escena de salvament de nàufrags per part de sant Pere Màrtir. Segons la Vida de Sant Pere de Tommaso Agni da Lentino (1255-1270), una nit fosca i boirosa una nau es trobava enmig d'una tempesta, durant la qual un mariner genovès va dir a tothom que s'havia de pregar al germà màrtir Pere. Llavors va aparèixer un ciri sobre I'antena de l'arbre mestre que va fer fora la boira, i de tanta llum que feia, semblava que fos de dia. Els mariners van mirar cap a popa i van observar que sobre la vela hi havia un home vestit com un predicador que havia de ser sant Pere. Enrico Pusceddu, «Il retablo di san Pietro martire e san Marco evangelista di Joan Figuera (1456-1477): un caso emblematico di pittura catalana "desplazada"», Rosa Alcoy (ed.), Art fugitiu: estudis d'art medieval desplaçat, Barcelona, Grup d'Investigació EMAC, Departa- autor de la taula central dedicada a la Mare de Déu del Lliri, retaule perdut de I'església de Sant Jaume de Càller. Morí pobre i la seva casa fou venuda a l'encant públic, comprada pel mercader Antoni Vidal i revenuda el 1479 a Ramon Silva. ${ }^{24}$

El retaule de sant Bernadí - avui dia a la Pinacoteca Nazionale de Càller- es compon del compartiment del mig, de tres escenes laterals a cada banda, de guardapols i de dues taules superiors (fig. 3). Tot sembla indicar que hi ha tres mans diferents: 1) el compartiment del mig seria del pintor més capaç, Joan Figuera; 2) la predel·la i les sis escenes laterals correspondrien a Rafael Tomàs, amb la intervenció també, en alguns punts, de Figuera; 3) el guardapols i les taules superiors (crucifixió i lamentació) correspondrien a una tercera mà. Segons Pusceddu, aquestes obres no eren al retaule original del 1456, sinó que hi van ser afegides posteriorment. ${ }^{25}$

La primera descripció del retaule la va fer el canonge Giovanni Spano I'any 1861, quan el dit retaule encara es trobava al convent de Sant Francesc. Entre el 1871 i el 1875 part de la teulada de l'església cau, i poc després I'edifici és enderrocat. Els béns que contenia es traslladaren al Museo Regio de Càller. El 1912 Carlo Aru recompon el retaule i hi afegeix taules provinents d'altres retaules que es trobaven al dipòsit del museu. En un primer moment, Aru identificà el retaule com a obra de Jaume Huguet (Valls, 1415 - Barcelona, 1492), el pintor de Valls. ${ }^{26}$ L'obra de Tomàs i Figuera ha estat classificada com a huguetiana des dels primers estudis, fet que confongué Aru. De fet, tots dos autors, Tomàs i Figuera, s'havien format en el mateix ambient que Huguet, o es formaren al seu taller 0 al de Martorell, que mor el 1452. Huguet ${ }^{27}$ havia treballat a Barcelona el 1434 i es traslladà a Saragossa del 1435 al 1445; del 1445 al 1448 el trobem a Tarragona, i el 1448 tornà a Barcelona, on tingué taller propi fins a la seva mort, el 1492.

Així doncs, el barceloní Rafael Tomàs — que, segons Pusceddu, trebaIlà principalment en les taules dels carrers laterals - havia de tenir un bon coneixement de les barques de pas del riu Llobregat. Aquests aspectes ens permeten suggerir que ell fou molt probablement l'autor de la taula superior del carrer dret del retaule, que representa l'escena del miracle de la capa i el pas del riu Mincio.

\section{L'escena del miracle de la capa i el pas del riu}

La taula que pintà Rafael Tomàs on s'escenifica el miracle de la capa i el pas del riu correspon a un dels miracles de sant Bernadí: durant la Quaresma de I'any 1420, mentre es trobava allotjat al convent de Santa Maria 

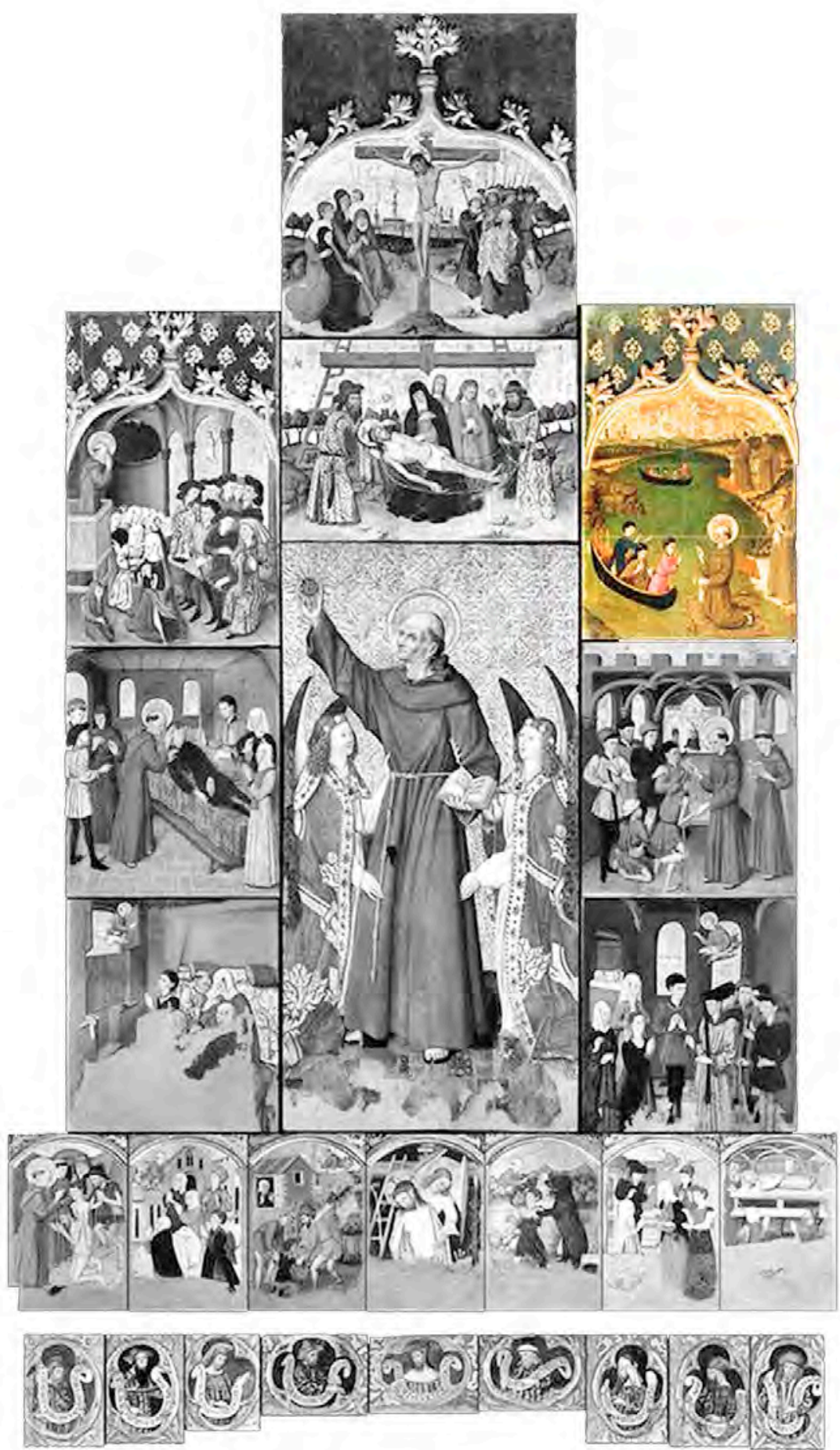

Fig. 3. Retaule de sant Bernadí, de l'església de Sant Francesc d'Estampatx. ment d'Història de I'Art, Universitat de Barcelona, 2014, p. 225-256; F. RuIZ QUESADA, Joan Figuera..., p. 36. Tot sembla indicar que el retaule sortí de l'illa de Sardenya a finals del segle XIX i que fou comprat pel colleccionista i antiquari Piero Tozzi a principis del segle xx i dut a Nova York; sembla que a la dècada dels noranta encara estava en mans $d^{\prime}$ un dels seus hereus familiars. Enrico Pusceddu, «I retabli sardi nella storiografia americana del primo Novecento: dai manoscritti inediti di Anna Rose Giles a Georgiana Goddard King", Alessandra PASOLINI (ed.), I retabli sardo-catalani dalla fine del XV agli inizi del XVI secolo e il Maestro di Castelsardo, Càller, Janus, 2013, p. 185; Enrico Pusceddu, Joan Barceló II (gia Maestro di Castelsardo). Questionidipittura in Sardegna intorno al 1500, tesi doctoral, Departament d'Història de I'Art, Universitat de Barcelona, 2014, p. 17, 82 i 359.

23 Alessandra Pasolini, «I fondi d'oro e i motivi tessili nel Maestro di Castelsardo e nei retabli sardi tra la fine del ' 400 e gli inizi del '500", A. PASOLINI (ed.), I retabli sardo-catalani..., p. 97 (Lucifer) i p. 99 (Presepio).

24 M. G. Scano, "Presències catalanes...», p. 248.

${ }^{25}$ C. ARU, «La pittura sarda...», p. 194-195; C. MALTE$\mathrm{SE}$, Arte in Sardegna dal $\mathrm{V}$ al XVIII, Roma, De Luca, 1962; C. Maltese, R. Serra, «Episodi di una civiltà anticlassica», F. BARRECA et al. (eds.), Sar- 
degna, Venècia, Electa, 1969, p. 133-364; Renata SERRA (amb la collaboració de R. Coroneo), Pittura e scultura dall'età romanica alla fine del 1500, Nuoro, Ilisso, 1990, p. 107; Enrico Pusceddu, «Un documento chiave per la ricomposizione del Retablo di san Bernardino di Cagliari», Matèria. Revista internacional d'Art, núm. 9, 2015, p. 39-60. Pusceddu proposa que dels dos pintors, el secundari, és a dir, Tomàs, és qui s'encarregà de fer les taules laterals i la predel.la. E. Pusceddu, «Il Retablo di san Bernardino...», p. 151-153.

${ }^{26}$ Carlo ARU, "Storia della pittura in Sardegna nel secolo $\mathrm{XV}$ », Anuari de l'Institut d'Estudis Catalans, vol. Iv, 19111912, p. 513-521; C. ARU, «La pittura sarda...», p. 161-223; Eva MARCH I RoIG, "Jaume Huguet», A. Pladevall i Font (dir.), L'art gòtic..., p. 105.

27 El retaule de sant Bernadí i I'àngel custodi de la capella dels esparters i els vidriers de la catedral de Barcelona fou realitzat entre els anys $1462 \mathrm{i}$ 1475, i desmuntat i reconvertit en respatllers de bancs a finals del segle XVII o principis del xVIII. Una de les taules representa el miracle del pas del riu Mincio de sant Bernadí; en aquest cas, apareix una barca, amb rem i escàlem com a sistema de propulsió, però sense cap corda, com és habitual en les barques de pas de riu. L'orla i la popa foren afectades per la conversió de retaule a banc. Una curiositat d'aquesta barca és la popa plana. Pau Verrié,
Grazie, va voler anar a predicar a Màntua, però per arribar-hi calia travessar el riu Mincio amb una barca de pas. Els barquers no solien cobrar als frares, però aquell dia li va voler cobrar, ell es negà a pagar, va estendre la seva capa sobre l'aigua i amb un o dos frares més van travessar el riu navegant sobre la capa.

El tipus de barca de pas representat per Rafael Tomàs, autor de l'escena del miracle del pas del riu Mincio, no es devia inspirar evidentment en les barques de pas del nord $d^{\prime}$ Itàlia — que dubtem que hagués vist—, sinó en les catalanes, i és molt probable que les hagués vist i utilitzat en un riu tan cabalós i proper a Barcelona com és el Llobregat, el qual tenia tota una sèrie de barques de pas en bona part del seu recorregut, des del delta fins a Martorell i més amunt (amb barques de pas durant els segles XIV i XV al Prat de Llobregat, Sant Boi - Cornellà, Sant Vicenç dels Horts - Molins de Rei, Sant Andreu, Martorell, Sant Feliu - el Papiol, Esparreguera - Olesa). ${ }^{28}$

Evidentment, les dues barques de pas representades no corresponen a les del riu Ebre, que disposen de ramalet i gúmena, sinó que tenen castell per al llibant, tal com eren les barques de pas del Llobregat i d'altres rius catalans. En el nostre cas, ens trobem amb el pas de barca, que a l'Edat Mitjana es constituïa d'un cap que enllaçava les dues ribes, lligat a banda i banda del riu en arbres, estaques o argues; aquest cap o llibant aguantava la barca que es desplaçava d'un costat a l'altre del riu i evitava que el corrent se l'emportés riu avall; per això la barca de pas també s'anomena barca de llibant. A l'escena del retaule objecte d'estudi no s'hi observa el ramalet, sinó que el Ilibant passa directament a través d'una estructura de fusta vertical situada a la proa de I'embarcació: el castell (fig. 4).

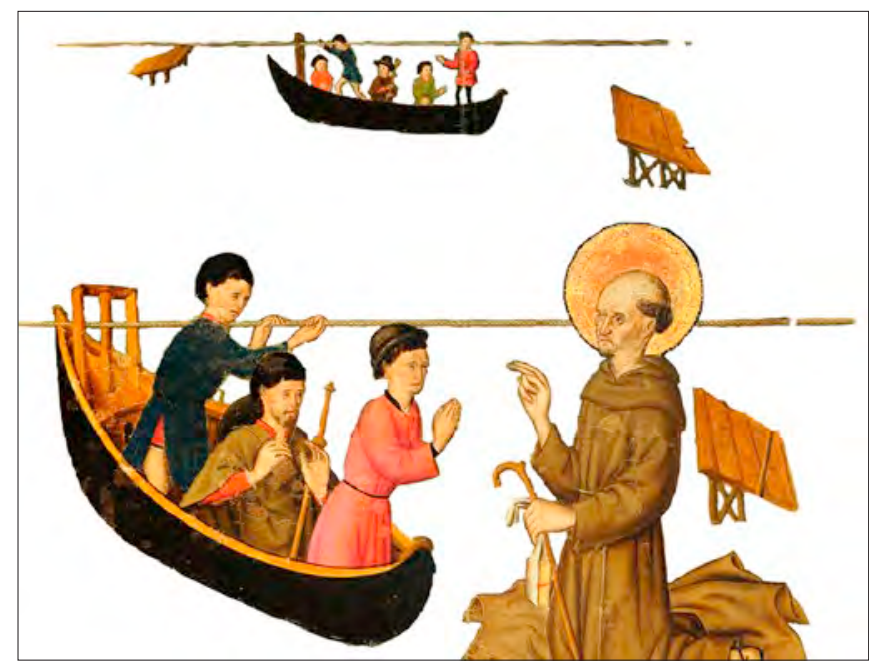

Fig. 4. Detall de l'escena del miracle del pas del riu Mincio. 
A banda dels elements esmentats, totes les barques de pas solien facilitar la càrrega i descàrrega de gent, mercaderies i animals, algunes amb taules de fusta que es podien posar i treure, d'altres amb una estructura fixa en forma de rampa o bé a la riba, que era el més habitual, o bé formant part de l'embarcació.

Per desplaçar-se s'ajudaven de perxes, una mena de bastons llargs amb què s'empenyia la barca des de la riba o bé contra el fons. També des de la riba s'estiraven caps per ajudar a acostar-la, i per allunyar-se de la riba solien utilitzar el timó i la força del corrent alhora, colllocant la barca esbiaixada respecte a la riba i a la direcció del corrent.

Aquestes barques les solien construir mestres d'aixa que es desplaçaven des dels pobles de la costa riu amunt fins a arribar a la població que les havia encarregat. També es podia donar el cas que el riu fos navegable en el tram que anava des de la desembocadura fins a la població on hi havia $d$ 'haver la barca de pas; en aquests casos, les barques es construïen als escars o tallers que tenien els mestres d'aixa a les seves poblacions d'origen $i$, un cop acabades, les conduïen per mar i riu fins al punt del pas de barca. Per aquest motiu les barques de pas no diferien de la resta de barques menors (ja fossin de pesca, de petit comerç de cabotatge o auxiliars de naus i galeres) $i$, en conseqüència, podem servir-nos de la rica iconografia naval existent a Catalunya sobre embarcacions de pesca dels segles XIV i XV. ${ }^{29}$

En les barques de pas, com en I'exemple de I'estudi, I'única diferència respecte a les barques marítimes és que cada barca disposa de castell a proa, a més del llibant que uneix les dues ribes passant pel castell de la barca i les rampes per embarcar i desembarcar.

Les barques tenen el buc negre, calafatejat amb pega fins a I'orla, que té el color natural de la fusta, marró clar, igual que tot l'interior. El buc no té simetria entre la meitat de proa i la de popa, sinó que té la proa llançada cap endavant i lleugerament més alta que la popa, on la testa de la roda fa un regirament en forma de S cap a popa. A l'interior de la barca s'aprecia el senó de proa, l'estructura que cobreix el terç de proa i pot servir per guardar-hi objectes, i que, a més, compleix la funció de suport per al castell, I'estructura de fusta tripartida per on passa el Ilibant. La barca té com a sistema de propulsió el barquer, que estira el llibant i amb la seva força desplaça la barca en direcció a la riba oposada — per tant, no calen rems ni vela-, per la qual cosa tampoc no cal timó; I'embarcació sempre es desplaça d'una riba a l'altra seguint el Ilibant. Aquesta seria una altra diferència respecte de les barques marítimes: a les barques de pas, el sistema de direcció i el de propulsió es troben al llibant.

A l'escena del retaule de sant Bernadí hi ha dues barques de pas i hi podem veure clarament la figura del barquer. En totes dues porta una
Joan AINAUd DE LASARTE, «Una 'nueva' obra de Huguet: el retablo de San Bernardino y el ángel custodio», Anales y Boletín de los Museos de Arte de Barcelona, Barcelona, Junta de Museus, vol. 1-2, 1942, p. 1133; E. MARCH I RoIG, «Jaume Huguet», p. 92-121; Joaquim GARriga i RierA, "Retaule de Sant Bernardí i I'àngel Custodi», Jaume Huguet, 500 anys, Barcelona, Generalitat de Catalunya, Departament de Cultura, 1993, p. 174-181.

28 Miquel Vives TorT, L'evolució històrica de la xarxa viària entre el Llobregat i el Foix. Des de l'època romana fins al tercer decenni del segle $x x$, tesi doctoral inèdita, Barcelona, Universitat de Barcelona, 2008, p. 501-507.

29 De barques de pesca que il.lustren passatges relacionats amb sant Pere i sant Andreu i el martiri de sant Vicenç, en podem trobar a: 1. Bíblia Sacra o de Vic, Nou Testament, f. 135, any 1268 (MEV). 2. Retaule de sant Vicenç, església de Sendes, segles XIV-XV (Museu Diocesà de la Seu d'Urgell). 3. Retaule de santa Marta, església d'Iravals, obra de Ramon Destorrents, Francesc i Jaume Serra, anys 1355-1361. 4. Retaule de sant Pere, església de Sant Pere de Cubells, obra de Pere Serra, anys 1362-1400 (Museo de Bellas Artes de Bilbao). 5. Retaule de sant Vicenç, església d'Estamariu, obra del Mestre d'Estamariu o Arnau pintor, any 1360 (MNAC). 6. Retaule de la Mare de Déu, monestir de Santa Maria de Si- 
xena, obra de Jaume i Pere Serra, anys 1363-1370 (MNAC). 7. Retaule de sant Pere i sant Andreu, església de Castellfollit de Riubregós, anònim de I'any 1400 (MNAC). 8. Retaule de sant Pere, Perpinyà (?), obra del Mestre del Rosselló (?) (Metropolitan Museum de Nova York). 9. Retaule dels sants $\mathrm{Vi}$ cenç i Agustí, església de Serdinyà, anònim del segle XV. 10. Retaule de sant Vicenç, església de la col-legiata de Sant Vicenç de Cardona, obra de Pere Vall, anys 1405-1411 (MEV). 11. Taula del profeta Isaïes i sant Pere, origen desconegut, obra de Pere Lembrí, anys 14101415 (The Hispanic Society, Nova York). 12. Retaule de sant Pere, església de Sant Pere de Terrassa, obra de Lluís Borrassà, anys 1411-1413 (Museuesglésia d’Egara, Terrassa). 13. Retaule de sant Francesc, església de Santa Clara de Vic, obra de Lluís Borrassà, anys 1414-1415 (MEV). 14. Retaule de Sant Pere, església de Sant Joan Baptista de Vinaixa, obra de Ramon de Mur, anys 14201421 (MDT). 15. Retaule de sant Miquel, la Seu d'Urgell, obra de Bernat Puig i Jaume Cirera, any 1433 (MNAC). 16. Retaule de sant Pere, església de Sant Pere de Ferrerons, obra de Jaume Cirera i Bernat Puig, anys 1431-1433 (MEV). 17. Retaule de sant Pere, església de Sant Pere de Púbol, obra de Bernat Martorell, anys 1437-1442 (Museu d'Art, Girona). 18. Retaule de sant Pere, església de Montagut, obra de Pere Mates, anys 1475-1500 mena de jaqueta fosca de màniga llarga que cau per sota de la cintura fins a arribar sobre el genoll; a la part de baix, en canvi, duu una mena de pantaló curt, perquè cal suposar que tot sovint havia de posar els peus a I'aigua. És I'únic personatge que porta les cames nues i els peus descalços.

Els passatgers van tots 0 bé drets o bé asseguts, amb vestits de més qualitat, alguns amb barret i d'altres amb un bastó o una vara. A la dreta i en primer pla, hi veiem sant Bernadí agenollat sobre la capa i passant per sobre les aigües del riu Mincio.

Completant I'escena, observem els llibants de cada barca que travessen el riu, i a les dues ribes, la presència dels embarcadors que facilitaven la càrrega i descàrrega de les barques, una mena de rampa inclinada feta de taules de fusta.

\section{Conclusió}

En la història de la tecnologia naval, i en concret la de I'Edat Mitjana, I'objecte preferent d'estudi solen ser les embarcacions marítimes (naus i galeres, i en menor mesura, llenys i barques), mentre que les embarcacions fluvials i lacustres són les grans oblidades. En bona part això es deu a la migradesa d'informació d'arxiu i literària d'aquestes en comparació amb les marítimes, però aquesta absència és molt més gran en la iconografia. Coneixem una gran quantitat de retaules que ens mostren naus i coques formant part de passatges i miracles de diversos sants (santa Úrsula, sant Nicolau, sant Martí de Tours, santa Magdalena, etc.) i barques de pesca (sant Pere i sant Andreu, sant Vicenç); en canvi, les barques fluvials són les grans absents.

Una imatge excepcional de les barques de pas fluvials baixmedievals I'hem d'anar a buscar a la Pinacoteca Nazionale de Càller, on es conserva el retaule de sant Bernadí de I'església de Sant Francesc d'Estampatx. El retaule, obra dels pintors catalans Rafael Tomàs i Joan Figuera, ens mostra una escena única: el pas del sant sobre la seva capa d'un costat a l'altre del riu Mincio. L'escena concreta del pas del riu sembla que va ser realitzada pel barceloní Rafael Tomàs, el qual, amb tota probabilitat, representà les barques de pas que havia vist al riu Llobregat a la primera meitat del segle XV.

Marcel Pujol i Hamelink Escola Superior de Conservació i Restauració de Béns Culturals de Catalunya mpujol12@xtec.cat 
Les barques de pas i el RETAUle de sant Bernadí de Siena (1455-1456) DE L'ESGLÉsia de Sant Francesc d’Estampatx (CÀller, Sardenya)

A l'Edat Mitjana hi havia diferents maneres de creuar un riu. Si era possible, les persones, els animals i els carros buscaven un pas o gual per on poder passar a peu, sempre que el corrent no fos gaire fort ni I'aigua passés de la cintura. Quan no es podia passar a peu, es construïen ponts o bé s'utilitzaven barques per passar d'una riba a l'altra. D'aquestes barques de pas $n^{\prime} h i$ va haver de dos tipus: el primer era utilitzat al riu Ebre i el segon, a la resta de rius catalans. El retaule de sant Bernadí del convent de Sant Francesc d'Estampatx (Càller, Sardenya) ens mostra una imatge totalment excepcional a la taula en què el sant travessa el riu Mincio. L'autor, el barceloní Rafael Tomàs, hi pintà una barca de pas de les que anomenem de Ilibant i castell, com les que coneixia del riu Llobregat.

Paraules clau: navegació, barca de pas, retaule, Baixa Edat Mitjana, Sardenya, Catalunya, Llobregat

The Boats of Passage and the Altarpiece of Saint Bernadino of Siena (1455-1456) from the Monastery of San Francesco di Stampace (Cagliari, Sardinia)

In the Middle Ages, there were different ways to cross a river. People, animals and carriages could either look for a pass or a ford, as long as the current was not too strong and the water level would not reach their waist, or, in some cases, bridges had to be built or they had to use a boat to get to the other side of the river. There were two kinds of boats of passage, the first one was used on the river Ebre and the second one on all the other Catalan rivers. There is an exceptional picture in the altarpiece of Saint Bernadino from the monastery of San Francesco di Stampace (Cagliari, Sardinia) that shows the saint crossing the river Mincio. The author, Rafael Tomàs, from Barcelona, painted a boat of passage, like the ones found on the river Llobregat.

Keywords: navigation, boat, altarpiece, Late Middle Ages, Sardinia, Catalonia, Llobregat
(Museu d'Art, Girona). 19. Retaule de sant Pere, església de Sant Pere de Reixac, obra dels Vergós, finals del segle XV (Museu Diocesà de Barcelona). 20. Retaule de la Mare de Déu, sant Joan Baptista i sant Pere, de I'obrador de Morella (?), any 1400 (Museu del Cap Ferrat, Sitges). 21. Retaule de sant Iscle i santa Victòria, església de Politg, anònim del segle Xv. 22. Retaule de sant Pere, València, obra de Roderic d'Osona el Jove, anys 1496-1515 (Museu de Belles Arts de València). M. Pujol i HAMELINK, «Tecnologia i pesca...», p. 156-168. 
Aquest article ha estat publicat originalment a Matèria. Revista internacional d'Art (ISSN en línia: 2385-3387)

Este artículo ha sido publicado originalmente en Matèria. Revista internacional d'Art (ISSN en línea: 2385-3387)

This article was originally published in Matèria. Revista internacional d'Art (Online IS S N : 2385-3387)

\section{MATÈRIA}

Revista internacional d'Art

Els autors conserven els drets d'autoria i atorguen a la revista el dret de primera publicació de l'obra.

Els textos es difondran amb la llicència de Reconeixement-NoComercialSenseObraDerivada de Creative Commons, la qual permet compartir I'obra amb tercers, sempre que en reconeguin I'autoria, la publicació inicial en aquesta revista i les condicions de la llicència: https://creativecommons. org/licenses/by-nc-nd/4.0/deed.ca

Los autores conservan los derechos de autoría y otorgan a la revista el derecho de primera publicación de la obra.

Los textos se difundirán con la licencia de Atribución-NoComercial-SinDerivadas de Creative Commons que permite compartir la obra con terceros, siempre que éstos reconozcan su autoría, su publicación inicial en esta revista y las condiciones de la licencia: https://creativecommons.org/licenses/ by-nc-nd/4.0/deed.es

The authors retain copyright and grant the journal the right of first publication.

The texts will be published under a Creative Commons Attribution-NonCommercial-NoDerivatives License that allows others to share the work, provided they include an acknowledgement of the work's authorship, its initial publication in this journal and the terms of the license: https://creativecommons.org/licenses/by-nc-nd/4.0/deed.en

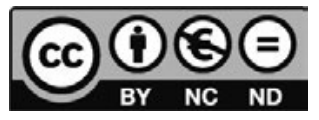

